\title{
Mireia Munmany Muntal, La gestió del patrimoni literari. Conceptualització $i$ anàlisi comparativa dels models català $i$ anglès, Tarragona, Publicacions de la Universitat Rovira i Virgili, 20I7, 230 p., ISBN: 978-84-8424-64I-I.
}

En un temps de reivindicació dels elements patrimonials i territorials en la literatura, de gir espacial en els seus estudis, veu la llum un treball ben oportú per a reflexionar sobre el concepte de patrimoni literari i l'abast de la seua gestió. Aquest llibre, que inaugura la col-lecció "Patrimoni Literari», dirigida per Magí Sunyer, editat per Publicacions de la Universitat Rovira i Virgili, té el seu origen en la tesi doctoral defensada per Mireia Munmany el 20I6 a la Universitat de Vic-Universitat Central de Catalunya, al si del Grup d'Estudis de Gènere: Traducció, Literatura, Història i Comunicació de la mateixa universitat.

La seua autora, Mireia Munmany Muntal (Taradell, 1982), llicenciada en periodisme (UAB), màster en gestió cultural (UB) i doctora industrial en Traducció, Gènere i Estudis Culturals per la UVic-UCC, ha treballat en l'àmbit de la gestió cultural tant a la Fundació Jacint Verdaguer com a la Fundació Miquel Martí i Pol, per la qual cosa combina els coneixements acadèmic i professional sobre la gestió de les cases museu d'escriptors.

Elllibre de l'autora taradellenca s'estructura en quatre capítols que aborden quatre nuclis de continguts: la conceptualització del concepte de patrimoni literari, la gestió del patrimoni literari, la comparació de la gestió del patrimoni literari a Catalunya amb Anglaterra i la valoració de la gestió del patrimoni literari català.

El primer capítol del llibre està dedicat, precisament, a la conceptualització del concepte de patrimoni literari. El patrimoni literari, entés com un factor de cohesió social, és definit a partir de la teoria dels polisistemes desenvolupada pel professor israelià Itamar Even-Zohar, el qual proposa una definició del patrimoni literari com un sistema dinàmic i heterogeni, constituït per una xarxa de relacions i tensions entre diversos elements: l'autor, l'obra literària, els editors, els acadèmics, els lectors, els gestors, 
els polítics, etc. Cercant-hi la precisió, l'autora opta per emprar el concepte de «(poli) sistema», que aplica tant al patrimoni literari com a la seua gestió, per evidenciar la multiciplicitat de sistemes existents dins un polisistema. La literatura es relaciona, a més, amb els processos de pertinença a un grup relacionats amb els conceptes d' «identitat col-lectiva», «identitat nacional» $i$ «memòria col-lectiva». El patrimoni literari ajuda, doncs, a entendre el present i organitzar el futur.

El concepte modern de patrimoni a Europa naix entre els segles XVIII i xIx lligat a la idea d'estat nació i es materialitza en museus (el British Museum, el Louvre, els Ufizzi i el Vaticà) que estableixen una nova interpretació de la història. Actualment, el terme ha eixamplat el seu abast i fins i tot es parla d'una inflació del concepte. De les etapes històriques de conservació i salvaguarda, hem passat a l'etapa actual caracteritzada per la gestió.

En el terreny literari, el concepte clau és el cànon d'interpretació de l'obra literària, imposat, de dalt a baix, per la cultura dominant. Precisament, es destaca el fet que la publicació en 1994 del Cànon occidental de Harold Bloom va coincidir amb un context acadèmic nord-americà que veia amb preocupació l'ascens dels estudis ètnics, culturals o multiculturals. En l'àmbit literari català, s'assenyala la Història de la literatura catalana, d'Antoni Comas, Joaquim Molas i Martí de Riquer (1984-1986) i la col-lecció MOLC, les «Millors Obres de la Literatura Catalana» com dues fites en l'establiment del cànon literari català. Complementàriament, un altre àmbit de transmissió del patrimoni literari el representa l'ensenyament. Les cultures nacionals valoren el patrimoni propi i el transmeten a les aules.

El segon capítol aborda la qüestió de la gestió del patrimoni literari, entesa per l'autora com a "procés de selecció, conservació, (re)lectura, anàlisi i organització del patrimoni literari. Un element imprescindible en el sentit que tradueix, (re)interpreta i transmet el llegat literari a la societat» (p. 6I). Abans de gestionar, en primer lloc cal seleccionar per a després (re)interpretar, entre la memòria i la modernitat, entre el local i el global.

Amb molt bon criteri, es tracta la qüestió del turisme literari com a recurs de desenvolupament econòmic i de creació de "marca». En el cas de la gestió del patrimoni literari, s'afirma que aquesta ha de respondre a les necessitats del turista cultural interessat tant per la vida dels autors com per la possibilitat d'experimentar una experiència real a partir de l'obra i l'entorn. S'ha dit que la gestió del patrimoni ha de presentar una «veritat» que batega «en el cor invisible del lloc en qüestió».

Els dos productes més visibles per a posar a l'abast del públic el patrimoni literari són, tal com s'explica, les cases museu i les rutes literàries. Les cases d'escriptors són un sistema de difusió de la memòria d'un autor, un «lloc literari» on es conserva 
i es respira l'univers creatiu i personal de l'autor, l' «aura» de l'escriptor, el seu valor simbòlic. L'autora aprofita per a diferenciar centres patrimonials, centres d'estudi i centres de difusió, segons el seu àmbit de treball. D’altra banda, les rutes literàries, tan emergents als nostres dies (tant en contextos de turisme cultural com educatius) permeten, a més, el diàleg amb l'autor en el seu context. A parer de Mireia Munmany, són també, seguint la formulació de Foucault, heterotopies, espais entre la utopia i la realitat, fora de qualsevol espai.

En el tercer capítol es fa una aproximació a l'estat de la qüestió del patrimoni literari a Catalunya en comparació amb la gestió que es du a terme a Anglaterra. D’Anglaterra s'hi fa esment a la gènesi i evolució de les blue plaques londinenques (actualment unes 900), des de la primera, instal.lada el I867, dedicada a Lord Byron. D'altra banda, existeixen unes àrees associades amb autors, anomenades «countries», com Shakespeare Country, Brontë Country, Hardy’s Wessex, etc. Dues associacions, el National Trust (Anglaterra, Gal.les i el Nord d'Irlanda) i l'English Heritage (Anglaterra) gestionen diverses cases literàries. En concret, s'hi analitza l'emblemàtic cas de Shakespeare a Stratford-on-Avon, el seu poble natal, atracció turística des del segle XVIII, la gestió del centre dedicat a les germanes Brontë a Haworth i la de la darrera casa on va viure Virginia Woolf, a Random, la Monk's House.

De Catalunya, d'altra banda, es mostra la gestió de dos dels centres patrimonials més consolidats: la Fundació Jacint Verdaguer, a Folgueroles, i la Fundació Josep Pla, a Palafrugell. En els darrers temps s'hi han generat propostes d'impuls de la literatura a través del turisme. En aquest context, la tasca del professor Llorenç Soldevila i el seu ambiciós projecte Geografia literària dels Països Catalans, completat amb la seua versió web, anomenada Endrets, resulta una eina decisiva. Hi cal sumar el Mapa literari català, creat per Espais Escrits en $20 \mathrm{IO}$ i un precedent de tots dos projectes: l'Atles literari de les terres de Girona (2003). A Catalunya les cases museu són de creació més recent que no a Anglaterra i es poden comptabilitzar més de 50 centres de diferent tipologia. El naixement d'Espais Escrits. Xarxa de Patrimoni Literari Català en 2005 aglutina setanta centres diferents i dona visibilitat als autors que conformen la xarxa (86 en 20I7), tant del seu llegat tangible com intangible: la seua casa, les seues obres i els seus paisatges. Si bé el 1993 la Fundació Josep Pla de Palafrugell creà la primera, la "Ruta Josep Pla», és a partir del 2005 que es posaran en circulació noves rutes literàries. La tasca de l'associació presenta quatre eixos: la comunicació de les activitats literàries a partir del web Espais Escrits (2007), la teorització sobre el concepte i la gestió del patrimoni literari (que culminà en el llibre Literatura, territori i identitat. La gestió del patrimoni literari a debat, 20II), l'oferta de serveis i l'aposta per les noves tecnologies. De totes les cases, la Fundació Jacint Verdaguer, a Folgueroles, es va convertir el 2009 
en el primer museu literari registrat a Catalunya. D’altra banda, la Fundació Josep Pla, a Palafrugell, segons dades de 20I5, atrau un públic anual superior a les I2.000 visites. El quart capítol es planteja una valoració de la gestió del patrimoni literari català a partir de la creació d'un mètode per a valorar el grau de gestió del patrimoni literari. Identificar els elements més influents que formen part de l'estructura dels factors del sistema. A partir del procés de canonització de l'obra d'un escriptor utilitzat per Enric Sullà (2015) que consta de quatre etapes: emergència, reconeixement, consagració i perpetuació, Mireia Munmany elabora una personal relació d'ítems que ha tingut en compte en l'anàlisi i la valoració del grau de gestió del patrimoni literari d'un autor determinat, agrupats en quatre àmbits: vida i obra, institució i acadèmia, salvaguarda patrimonial i memòria i difusió social. L'esquema proposat, una de les aportacions centrals del llibre, inclou l'existència de centres de gestió de patrimoni literari i apunta aspectes com les activitats entorn de la memòria d'un escriptor, la presència del seu nom en carrers, institucions o monuments, la presència en biblioteques públiques, en clubs de lectura, en projectes TIC, etc.

En l'apartat de conclusions finals, es considera el paper d'una bona gestió per a capgirar la situació d'invisibilitat literària i la necessitat de recursos per a reivindicar aquest camp i situar-lo en la centralitat del sistema cultural. S'hi ofereixen finalment unes línies de recerca, que ens semblen particularment interessants. En primer lloc la necessitat de tractar més a fons el concepte de «lloc literari», un aspecte clau en la relació entre literatura i espai sobre el qual no s'ha fet una especial incidència. Una altra tasca que es considera pendent d'anàlisi és la comparació de la gestió del patrimoni literari català amb altres països, una qüestió sobre la qual la xarxa Espais Escrits ha manifestat el seu interés, i l'oportunitat d'aplicar el mètode (poli)sistèmic a diversos autors. Com a conclusió, l'autora planteja una estratègia de gestió global al voltant del patrimoni literari català, per a la qual cosa proposa fomentar el diàleg entre patrimoni literari i educació, patrimoni literari i turisme, patrimoni literari i societat en general. Entre d'altres funcions, els centres patrimonials poden ser llocs per aprendre, llocs on fer pràctiques professionals.

Un dels encerts del llibre, que ja era present en el text de la tesi sobre la qual es basa, és la inclusió de la transcripció de les entrevistes amb protagonistes clau del patrimoni literari català (Anna Aguiló, Laura Borràs, Vinyet Panyella, Llorenç Soldevila, Magí Sunyer, Carme Torrents i Mariàngela Vilallonga), que aporten una visió molt significativa. Així, per exemple, el professor Llorenç Soldevila presenta elements per a l'anàlisi com la pèrdua de valor social de la literatura. El turisme cultural i l'ensenyament són, al seu parer, la clau del patrimoni literari. I mentre considera que va a l'alça el turisme cultural, té la impressió que ha perdut pistonada en el món 
de l'ensenyament. Mentre en els anys noranta podia emportar-se els seus alumnes de secundària quinze dies a les illes Balears, ara cada dia és més difícil traure els alumnes de l'aula. O, parlant d'un altre tema, i com a detall paradigmàtic, en relació amb el concepte de marca, Carme Torrents esmenta el cas d'un dolç de Folgueroles (la Coca del Mossèn), que ha esdevingut un element turístic local, de la mateixa manera que la Casa Museu Verdaguer oferereix, a un altre nivell, una operació de prestigi, d'autoritat cultural i moral sobre la figura de l'escriptor, amb la missió de vetllar tant pel que és tangible com intangible.

Considerem, en definitiva, que un dels molts encerts del llibre és aquesta visió aglutinadora d'elements diversos, des de la gestió cultural, passant pel turisme literari i l'educació fins a aspectes més propis de la teoria literària. De vegades, això sí, hem detectat un estil expositiu excessivament dependent del discurs o registre acadèmic (com es mostra a la p. I59 quan s'al.ludeix autoreferencialment al llibre com una «tesi»), amb la presència de certes repeticions que fan ressentir l'estil assagístic general. Coincidim en el missatge de fons expressat per l'autora que reclama la necessitat d'una bona estratègia col-lectiva per tal que el patrimoni literari català siga visible mitjançant una estratègia de gestió global. Fem extensiu, això sí, aquest desig a tots els territoris de parla catalana, on els centres patrimonials, més escassos i puntuals, han experimentat en els darrers anys un procés de revitalització semblant al descrit per a Catalunya.

\author{
Alexandre Bataller Catalì \\ Universitat de València \\ alexandre.bataller@uv.es \\ ORCID oooo-0003-I73I-7592
}


